American Journal of Educational Research and Reviews
(ISSN:2474-9265)

\title{
Adult Learning Theory: Reflections on the role of mentoring as a key to success in advanced degree programs
}

\author{
Kent L. Willis, PhD
}

The University of Texas Health Science Center at Tyler.

\begin{abstract}
Vital to completing advanced educational and training programs beyond the undergraduate degree level is realizing specific dispositions and traits. In this paper, the role of mentoring as a critical contributing factor to student success is examined through critical reflection as a form of qualitative inquiry. Traditionally utilized in professional settings to improve practice, critical reflection provided an emergent methodological approach for close examination of personal experiences with mentoring during the learning process in pursuit and subsequent completion of a professional degree (Fook, 2013). This in-depth examination of personal experience derived lessons learned from individuals that successfully navigated the rigor of advanced educational programs to expose mentoring's role as the key to success.
\end{abstract}

Keywords: Adult learning theory; Self-direct learning; Selfdirected learning; Andragogy; Critical reflection methodology
${ }^{*}$ Correspondence to Author:

Kent L. Willis, PhD

The University of Texas Health Science Center at Tyler.

(903) 877-7959

How to cite this article:

Kent L. Willis. Adult Learning Theory: Reflections on the role of mentoring as a key to success in advanced degree programs. American Journal of Educational Research and Reviews, 2021; 6:80.

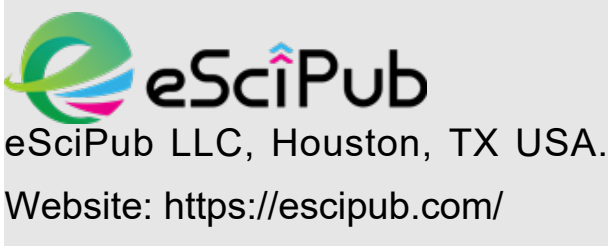




\section{Introduction}

Understanding the attitudes, feelings and beliefs of adult learners is vital to the development and sustainability of graduate and professional (advanced) degree programs. Engaging adult learners in reflection on the processes and procedures reveals rich data to inform the decision-making process and test theory. Reflection as a professional practice is not a new term but, utilization as a methodology is emerging as an innovative approach to uncovering the nuances of experience that may be harder to capture through traditional research approaches. This study provided recent graduates of advanced study with the opportunity to engaged in introspective analysis provided for analysis to understand takeaways that assist in ongoing improvement efforts.

\section{Statement of the Problem}

Mentoring is a key component of adult learning theory that contributes to student success. The problem is that the literature lacks the voice of learner reflection on the nuances of guidance and support that contributed to success beyond the curriculum and traditional student support services. Furthermore, this investigation sought to derive practical advice to inform the practice of mentoring in adult education. Subsequently, the findings reveal challenges faced by learners as they navigated the challenge of scholarship (Mullen et al., 2010).

\section{Review of Literature}

The brief literature review underpinning this study examined the nexus of mentoring and adult learning theory through three different lenses: 1) mentoring and adult education, 2) mentoring to advance careers, and 3 ) mentoring to improve outcomes. Building on existing literature helps situate the study within the context of prior research and theory.

\section{Mentoring and Adult Education}

Chinnasamy (2013) explains that adult learning theory and self-directed learning are popular in western countries and that andragogical approaches highlight the mentoring aspect. In the examination of a mentoring program initiated by the London Fire Brigade (LFB) in the United
Kingdom, findings support the postulation that andragogy is an optimal lens for the consideration of mentoring in adult education. The practical nature of andragogy sets it apart from other behavioral methods of learning. In the case of LFB training, the self-direct learning required participants to exhibit the following skills: (1) be a self-starter, and (2) engage in collaboration with mentors to solve problems (hence mentoring). Diverging radically from traditional pedagogical approaches to teaching children, adult education views the teacher as a facilitator of the learning process. Historical roots of adult learning stem from the work of Malcom Knowles (Knowles et al., 2014).

Henry (2011) affirms that the American adult educator Malcolm Knowles' development of practical-theoretical framework laid the foundation through seminal works published between 1950-1995. Malcolm Knowles's effort to advance pedagogical knowledge in adult education continues as a formidable research area to improve teaching and learning.

\section{Mentoring to Advance Careers}

Mentoring is a recognized intervention to effectively assist professionals in career development and advancement. Tran (2014) examined the role of mentoring to assist women of color to advance towards faculty positions in higher education. The cross-case analysis conducted at a Hispanic Serving Institution revealed that mentoring can be a strategy for broader institutional change. Chinnasamy (2013) also confirms the interrelated nature of mentoring and adult learning that emerged in the framework of Malcolm Knowles.

Cooke (2018) revealed the effectiveness of mentoring to develop professionals in a study of a teacher development program. The ability to challenge personal assumptions was a key finding from the study that examined the utility of reflective practice as it relates the development of mentor and mentee relationships in the process of professional development. Further, the willingness of mentees to accept the expertise of mentors proved critical to success.

\section{Mentoring to Improve Outcomes}


If an adult is aware that they are learning new skills, they would be willing to participate more in discussions in the classrooms and in the learning contexts. Unlike children, adults tend to take more responsibility for their own learning and would appreciate collaborative learning situations.

Within the adult learning context, mentoring is critical to learning prospects-it accords learners the opportunities for personal, academic and career development as mentees can expand their knowledge in the companies of their mentors. According to Cohen and Galbraith (1995), for adult learners, sponsored mentoring is a planned intervention that organizes mentormentee matches and focus on the mutual commitment of the participants on creating a functional dyadic that maximize the prospects of learning of the mentees. For adults, Cohen and Galbraith (1995) realized that mentors act as considerable sources of influence that help them learn from a variety of educational, training and employment possibilities available. More precisely, and as observed in the study, Cohen and Galbraith (1995) indicate that one-to-one mentoring is a model in harmony with life-long learning philosophy of adult continuing education.

Mullen et al. (2020) documents that for adult mentor-mentee relationship, the image of the journey greatly portrays the mentor-mentee experience. It is metaphoric since the mentee is considered to be on a journey of self development while the mentor is considered the 'wise teacher' with instructional and guidance capabilities. Daloz (1986) indicates that the mentees are do not explore the world in isolation; the mentors are critical components of the voyage. For instance, from the mentor, they can get specific feedback about the path and direction on how they are currently performing. For the andragogic model to work, the relationship should be mediated by a number of factors including mutual trust, accurate and reliable information, realistic exploration of the goals, challenges of ideas, holistic support (intellectual, psychologic- al and emotional), and encouragement.

\section{Theoretical Perspective}

A myriad of seminal concepts and frameworks add to the changing utility of critical reflection as an optimal approach to gauge the fidelity of mentoring as a construct of adult learning theory. On the topic of adult learning, Andragogy coined by Malcolm Knowles is synonymous with adult learning theory. Henschke (2011) explains Andragogy as "the art and science of helping adults learn." Criticism of Andragogy by adult education scholars' hinges on the lack of empirical research (Chinnasamy, 2013). Burge (1988) indicates that the framework failed to cover some of the fundamental learning theories and assumptions about whether adult learning differs markedly from child learning. For instance, Knowles (1984) moved beyond theory, indicating that it appears more as a system of thoughts than a heuristic. While Knowles considered Andragogy as different from pedagogy, there are situations when the two approaches are appropriate depending on the learner's situation and needs.

These findings are consistent with a study by McGrath (2008), which observes that adult learners often need to understand the reason for learning new knowledge before participating. For instance, McGrath (2018) introduces the idea of evening courses and how it influences professional development. For adults to consider such courses, employers have to convince them about the suitability of such courses to their professional experience-they need to have evidence of the qualifications. This has largely worked in management, marketing and accounting-where students in the classroom are encouraged to adapt work-based projects.

Materials and Methods: Fook (2011) defines critical reflection as "a way of learning from a reworking of experience". Critical reflection exists as a process of learning from experience to improve professional practice. The strength of critical reflection as a methodological approach are depicted in the chart below. 
Furthermore, critical reflection invites integration of practical approaches in adult teaching and learning into the domain of research with more pragmatism. The overarching research question guided the methodological approach and inquiry.

\begin{tabular}{|c|l|}
\hline Aspect & \multicolumn{1}{|c|}{ Description } \\
\hline Expression & $\begin{array}{l}\text { Expression of deeper and more complex nature of human experiences attributing to } \\
\text { improved understanding. }\end{array}$ \\
\hline Improvement & $\begin{array}{l}\text { Improved practice based on candid personal descriptions of the attitudes, feeling, and } \\
\text { beliefs manifested during the teaching and learning process. }\end{array}$ \\
\hline Operationalize & $\begin{array}{l}\text { Mechanism to operationalize theory to practice through the extension of the body of } \\
\text { knowledge around adult learning research and evaluation. }\end{array}$ \\
\hline
\end{tabular}

$R Q$ : What was the role of mentoring on the professional development leading to the successful completion of an advanced degree program?

The above-mentioned research question directed inquiry that prompted critical reflection by three individuals who recently completed advanced degree programs in health and education. Focusing on the role of mentoring was possible through semi-structured, openended questions discussing activities, interaction, communication, and investment by individuals identified as mentors by the participant. Patton (2017) elucidates that qualitative research design permits the in-depth exploration of experiences, attitudes, and beliefs derived from a shared experience of human beings. Understanding the underlying perspective of recent advanced degree program graduates may reveal meaningful information to improve mentoring and support for adult learners. The following four steps summarize the methodological approach underpinning this study.

- Step 1: Define the overarching research question.

- Step 2: Examine existing literature and theory.

- Step 3: Collect and analyze the critical reflection narrative

- Step 4: Review the results and draw conclusions.

\section{Sample Population}

Participants in this study self-identified demographic information. The parameters for inclusion relied on the completion of an advanced degree in health or education and willingness to disclose information relating to the nature of mentoring on the support network that attributed to the successful matriculation through curriculum and practical experiences.

Demographics of Participants

\begin{tabular}{|c|c|c|c|}
\hline Participant & Degree-Level & Ethnicity & Gender \\
\hline Participant \#1 “Jack” & Masters Level & Hispanic & Male \\
\hline Participant \#2 "Mary" & Doctoral Level & Caucasian & Female \\
\hline Participant \#3 “Thomas” & Doctoral Level & African American & Male \\
\hline Participant \#4 "Susan” & Masters Level & African American & Female \\
\hline
\end{tabular}

\section{Ethics and Confidentiality}

The participants in this study are protected by the development of pseudonyms and the omission of any information that might jeopardize the anonymity of any specific institution or individual. Ethical considerations and confidentiality are vital to the research process and this study followed best practices in the development of this manuscript. Participants volunteered to engage in audio recorded critical reflection that was saved on a password protected device and deleted following the transcription and analysis of the data. 
Results and discussion: The findings from this study reveal that mentoring was a critical element contributing to the success of students in advanced degree programs. Particularly the development of meaningful relationships build trust between the faculty and learner which resulted in collaboration and ultimately effective instruct- tion, coaching, and guidance. The analysis of transcripts presented below resulted in the development of three emerging themes that include (1) adult learners thrive on trusting relationships, (2) adult learners prefer practical application of theoretical knowledge and (3) adult learners should be recognized as colleagues in the knowledge enterprise.

\section{Theme 1: Adult Learners Thrive on Trusting} Relationships

Each of the four study participants made mention of the need for developing trusting relationships with faculty members during the learning process. Notably, Jack stated "I was most successful in courses led by instructors who built trust with the class when it comes to the grading and assessment procedures" noting the importance of clearly articulated expectations and evaluation of performance. Susan said "it was difficult for me to be successful in classes that seemed ambiguous as to what was expected beyond the syllabus discussion on the first day"

From the study, it appears that mentors act as a source of parallel academic learning that greatly help expand instructional capabilities beyond the classroom. Additionally, for adult learners, the mentors act as significant role models to the learning process-they psychologically and emotional supplement the learning experiences of the group and deviate from the 'nobody cares' attitude that is a convention in many of the secondary learning and settings. For the dyadic relationship to work for adult learners, however, there is need for them to establish some trust. The respondents indicated that an honest interaction with their mentors was critical to the learning process-they enjoyed learning when their mentors where highly supportive. This is established in the literature.
Theme 2: Adult Learners Prefer Practical Application of Theoretical Knowledge

Three out of the four participants touched on the need for practical application of the material being presented in instructional modules. Specifically, Thomas said "It would be much more effective if faculty member would focus on practical application of theory." Mary concurred with the sentiment about the need for practical application of material asking, "How do faculty members expect us to understand theory unless they provide real world examples at the onset?". Susan said "the best classes of my entire program took a practical approach and helped situated the information in a real-world context which was helpful for learning complex theories."

Theme3: Adult Learners Should Be Recognized as Colleagues in the Knowledge Enterprise

All participants spoke positively about the recognition of professional experiences and roles within the teaching and learning process. Jack reveled that "it feels good when the professor asks you to share with the class your experience from life and just careers". Mary said "my background as a professional is the reason that I pursued advanced study and that is worth something". Thomas explained that "my point of reference is based on my professional background and it is helpful when it relates to the coursework in a way that allows me to insert my prior knowledge and experience".

In conclusion, mentoring remains a critical component of pedagogy at the advanced degree level. Seminal adult learning theory confirms the lasting impact of Andragogy and the work of Malcom Knowles fully acknowledging the existence of some limitations presented in critique. This study confirms the need for intentional efforts to build meaningful relationships with learners that result in trust, examine curricular content to ensure that it is relevant to improve real world challenges and finally, students at the advanced degree level deserve to be respected as key contributors to the learning process based on prior life experience and proclivity for learning beyond the 
undergraduate degree. Suggested strategies that dovetail with the findings from this study regarding the utility of mentoring include the following tactics:

Faculty members should intentionally build trusting relationships by explicitly expressing a commitment to student success. Adult learners may struggle with self-doubt or uneasy feelings about balancing the demands of higher education and scholarship. Reassuring the learner that they are not alone in the process may provide affirmation and a sense of belonging.

Advanced degree coursework should include the practical application that will allow students to connect the classroom activities with realworld problems. Learners will find the academic journey more fulfilling when they can improve daily processes and procedures by applying knowledge and skills from the degree program and subject-matter expertise.

Students at the graduate and professional level bring life experience and work history to the classroom to enhance the overall learning experience. The discussion and assignments benefit when students share insights and perspectives that they have gained through professional activities and training, leading them to pursue advanced education.

Further research to promote strategies tailored to meet adult learners' needs should expand to sample populations from specific demographic groups. As more students enroll in graduate and professional degree programs, the demand grows for support programs that serve faculty and students' unique needs at the professional level.

\section{References}

[1] Bashan, B., \& Holsblat, R. (2017). Reflective journals as a research tool: The case of student teachers' development of teamwork. Cogent Education, 4(1), 1374234.

[2] Chinnasamy, J. (2013). Mentoring and adult learning: Andragogy in action. International Journal of Management Research and Reviews, 3(5), 2835.

[3] Cohen, N. H. (1995). The Principles of Adult Mentoring Scale. New directions for adult and continuing education, 66, 15-32.

[4] Cooke, D. M. (2018). The influences of professional development, in educative mentoring, on mentors' learning and mentoring practices (Doctoral dissertation, Auckland University of Technology).

[5] Fook, J. (2011). Developing critical reflection as a research method. In Creative spaces for qualitative researching (pp. 55-64). SensePublishers.

[6] Henry, G. W. (2011). Malcolm Shepherd Knowles: A history of his thought. Nova Science Publishers.

[7] Henschke, J. A. (2011). Considerations regarding the future of andragogy. Adult Learning, 22(1), 34-37.

[8] Knowles, M. S., Holton III, E. F., \& Swanson, R. A. (2014). The adult learner: The definitive classic in adult education and human resource development. Routledge.

[9] McGrath, V. (2009). Reviewing the Evidence on How Adult Students Learn: An Examination of

[10] Knowles' Model of Andragogy. Adult Learner: The Irish Journal of Adult and Community Education, 99, 110.

[11] Mullen, C. A., Fish, V. L., \& Hutinger, J. L. (2010). Mentoring doctoral students through scholastic engagement: Adult learning principles in action. Journal of Further and Higher Education, 34(2), 179-197.

[12] Patton, M. Q. (2015). Qualitative research \& evaluation methods: Integrating theory and practice.

[13] Tran, N. A. (2014). The role of mentoring in the success of women leaders of color in higher education. Mentoring \& Tutoring: Partnership in Learning, 22(4), 302-315.

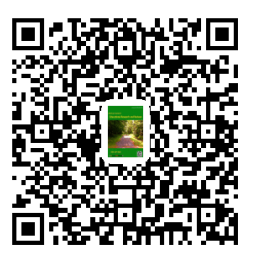

